Polky, Plannlny, and Reasarch

WORKING PAPERS

Dabt and International Flnance

International Economics Department

The World Bank

August 1989

WPS 251

\title{
Patents, \\ Appropriate Technology, and North-South Trade
}

\author{
Ishac Diwan \\ and \\ Dani Rodrik
}

The debate about stronger enforcement of patents on intellectual property rights assumes that the technological needs of the North and the South are similar. What happens to the debate when we allow for different technological preferences in the North and in the South? 
At the heart of the debate about intellectual property rights (IPRs) that is consuming so much attention in the Uruguay Round of trade negotiations is one basic economic issue. Most patented products or processes that make it to Southern markets are developed in the North. It is therefore believed that the North would profit from tighter patent procedures in the South, to protect Northem firms from imitators in their export markets - and that the South would like to pay as little as possible for these innovations, which lax patent procedures allows. It is recognized that this reduces the incentive for $R \& D$ in the North, but as long as the South :: a small part of the market, free riding does little harm.

In this paper, Diwan and Rodrik bring another feature to the debate: the possibility that the North and South may have differing technological needs. Just as the North would like to develop drugs against cancer and heart disease, and the South drugs against tropical disease, so the North's labor-saving innovations are less useful in the South, where labor is cheap.

Southern patents might promote the development of technologies appropriate to the South that might not have been developed if there were no patents. In this case, lower patent protection in the South would not benefit the South - and increased patent protection in the South can hurt the North when the resources that go into R\&D are limited.

Diwan and Rodrik develop a formal model for IPRs, emphasizing the dimension of technological choice. This model allows for a continuum of potential technologies, with a range of preferences in the North and South; free entry into the R\&D sector rather than duopolistic competition between two firms; and gradations of patent protection. It assumes that both markets are segmented, due to different patentlaw application in the two regions.

Some of the usual free-rider considerations must be qualified if the analyst considers the possibility that patent laws in the two regions affect both the quantity and quality of innovation. This becomes importan' when the two regions have different technological needs.

What are the results of the analysis? First, an increase in patent protection in either region leads to an increase in innovative activity, as well as a greater fit between the available technologies and the preferences of the patenting region. By implication, this skews the technology range away from the needs of the othe region.

Second, although a strictly utilitarian global welfare function would assign identical rates of patent protection to the North and South, placing greatcr weight on the welfare of the South necessitates differential treatment. But it is not clear a priori whether the South ought to have a lower or higher level of protection than the North.

Third, when patent rules are set in an uncoordinated manner, it is possible that a narrowing of the gap between the technological preferences of the two regions will lead to lower rates of patent protection in both the North and the South. Similarly, an increase in the relative market size of the South can lead to a reduction in patent protection in both regions.

This paper is a product of the Debt and International rinance Division, International Economics Department. Copies ane available free from the World Bank, $1818 \mathrm{H}$ Street NW, Washington DC 20433. Plcase contact Sheila King-Watson, room S8029, extention 33730 ( 37 pages with charts and tables).

The PPR Working Paper Series disseminates the findings of work under way in the Bank's Policy, Planning, and Research Complex. An objective of the series is to get these findings out quickly, even if presentations are less than fully polished. The findings, interpretations, and conclusions in these papers do not necessarily represent official policy of the Bank. 


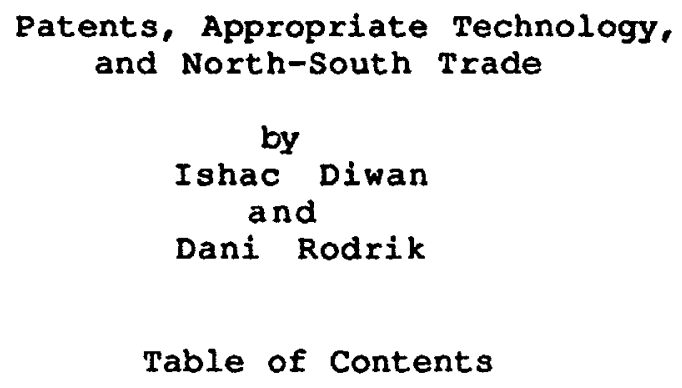

Table of Contents

I. Introduction 1

II. Preliminaries 4

III. Comparative Statics for the Range of Technologies 8

IV. Welfare Analysis $\quad 14$

$\begin{array}{ll}\text { v. The Nash Equilibrium } & 19\end{array}$

VI. Concluding Remarks $\quad 29$

$\begin{array}{ll}\text { Appendix } & 31\end{array}$

$\begin{array}{ll}\text { References } & 33\end{array}$

$\begin{array}{ll}\text { Tables } & 34\end{array}$

Figures $\quad 36$

We thank stanley Fischer for asking the question, and Refik

Erzan for stimulating our thinking on the subject. 


\section{Introduction}

One of the contentious North-South issues under discussion in the current rou..d of GATT negotlations concerns the protection of intellectial property rights (IPRs). The U.S., European Community, and Japan are in broad agreement that the international trading system provides inadequate protection to IPRs, and have put forth a number of proposals to tighten restrictions; poorer countries, whose practices would be most Immediately affected, oppose these proposals on the grounds that they would increase the profits of monopolistic forelgn firms at the expense of domestic consumers.

Under the present regime, IPRs are largely beyond the scope of the GATT, and fall under the jurisdiction of the World Intellectual Property Organization (WIPO), a U.N. agency. It is WIPO that oversees the existing international agreements on IPRs such as the Paris Convention (on patents) and the Berne Convention (on copyrights). The Paris Convention requires member states, under the national treatment principle, to apply the same criteria to foreign firms as to domestic ones, but does not prescribe specific levels of patent protection. Most of the ninety-eight members of the Convention are in fact developing countries. But the developed countries argue that the prevaling practices in the South leave much to be desired. Among complaints voiced by the former are: selective sectoral coverage in national legislation; inadequate remedies and sanctions in case of infringement of IPRs; procedural and administrative difficulties impeding acces; to courts; and arbitrariness and discrimination in the application of domestic statutes. Developing countries like Brazil and India in turn stress the possible exacerbation of monopolistic practices by Northern firms were patent protection to become more stringent. Therefore, they resist GATT involvement in IPRs, and prefer to use WIPO, whic'.1 lacks enforcement power, as the forum for discussion of such 
issues. 1

The basic economic issue that underlies the conflict of interest is easy to see. ${ }^{2}$ Most patented products or processes that make it to Southern markets are developed in the North. The North would therefore profit from tighter patent procedures in the South, as this would protect Northern firms against imitators in their export markets. According to the U.S. International Trade Commission, U.S. firms lose around $\$ 8$ billion annually from patent and copyright infringements (cited in Baldwin, 1988). But by the same token, the South would like to pay as little as possible for these innovations, which is what lax patent protection achieves. To be sure, this in turn reduces tine incentives of Northern firms to invest in R\&D. As long as the South is a small part of the world market, however, the adverse effects of its policies on global innovative activity are also smell, and free riding on the North makes eminently good sense. As a recent paper by Chin and Grossman (1988) demonstrates, it may be in the South's interest to provide no patent protection whatsoever.

In this paper we analyze this conflict of interest by bringing into consideration another feature of some importance. This new feature consists of the possibility that the North and South may have differing technological needs: the North would like to develop drugs against cancer and heart disease, whereas the South benefits more from drugs against tropical diseases; labor is cheap in the South but expensive in the North, so the North's labor-saving innovations are less useful in the South. When R\&D resources that can be

1. This discussion is drawn from various GATT sources. See also Baldwin (1988), Benko (1988), Hamilton and Whalley (1988), pp. 28-29, and Kelly et al. (1988), p. 39.

2. For an early statement of the issues, see Penrose (1951), especially chaps. VII and X. 
deployed in support of these Innovations are limited, cholces have to be made as to which areas will receive greater emphasis. Now Southern patents may have a role to play in promoting the development of technologies uppropriate to the South that would not have been developed in the absence of these patents. ${ }^{3}$ This incentive now competes against the free-riding motive. As we shall see, one implication is that a benevolent global ?lanner who puts a greater weight on the South's welfare than on the North's would no longer necessarily allow lower patent protaction in the South. Another implication of the potential competition for suitable technologies is that increased patent protection in the South need not always be good for the North.

The only other formal model devoted to IPRs in the North-South context that we are aware of is the one by Chin and Grossman (1988). These authors consider the competition between two firms, one each form the North and South. The Northern firm can invest in process innovation, which the Southern firm can copy costlessly when the South provides no patent protection. Our framework differs from theirs in a number of respects. We allow for a continuum of potential technologies, with a different distribution of preferences over them in the two reglons. This framework can be interpreted in terms of product, as well as process, innovation. Second, our model has free entry into the R\&D sector, rather than duopolistic competition between two firms. Third, we allow gradations of patent protection, which is more general than the simple hinary choice (protection or no protection) analyzed by Chin and Grossman. Finally, we assume that the Northern and Southern

3. This point was recognized early on by Vernon (1957, p. 12): ".. there is a case to be made that inventors in the industrialized areas of the world may need some special incentive to concentrate their talents on products of special utiity to the underdeveloped areas." 
markets are segmented, dus to differential patent-law application in the two regions. All of these features appear to be desirable ones. Their cost is that, unlike Chin and Grossman, we do not get snto the detalls of the strategic interactions between Northern and Southern firms competing in oligopolist1c markets.

\section{Preliminartes}

We allow for an unlimited spectrum of potential technologies, indexed by the continuous variable $\theta \in(-\infty, \infty)$. The range of discovered technologies, characterlzed by a lower bound $\theta$ and an upper bound $\bar{\theta}$, is endogenous and denoted by $[\theta, \bar{\theta}]$. We limit the analysis to uninterrupted ranges (1.e. no "holes" are allowed in the range).

Consumers are differentiated by taste, with each having a preferred variety of technology. ${ }^{4}$ Consumers can therefore also be indexed by their preferred $\theta$. To keep things simple, we assume each consumer gets utility of 1 If his prefered technology is available, and 0 otherwise. Letting $u(\theta)$ stand for the utility of consumer with preferred technology $\theta$, we have:

(1) $u(\theta)- \begin{cases}1 & \text { if } \theta \leq \theta \leq \bar{\theta}, \\ 0 & \text { otherwise. }\end{cases}$

Northern crnsumers are distributed according to the continuous distribution function $B(\theta)$ with support $(-\infty, \infty)$. Aggregate consumer welfare in the North

4. The use of the term "consumer" here is perfectly general, and applies equally weil to producers who are downstream users of technology. If we interpret the set of technologies as pertaining to a particular economic activity, $\theta$ could measure the required capital-labor ratio, the level of skilled labor needed, the expected life of the equipment, and so forth. Or, $\theta$ could simply index different products. 
can then be written as a function of the range of discovered technologies:

(2) $U^{n}(\theta, \bar{\theta})-\int_{-\infty}^{\infty} u(\theta) B(\theta) d \theta=\int_{\theta}^{\theta} B(\theta) d \theta$.

where we have used (1). For the moment, rothing specific need be assumed about the shape of $B($.$) . But it will help to think of B($.$) as a single-$ peaked, symmetric distribution such as the normal.

Consumers in the South are parameterized in same manner, except that we assume the distribution function for Southern consumers is centered on a mean to the right of that of the North. Further, the mass of Southern customers is a fraction $\gamma$ of those in North $(\gamma<1)$, with $\gamma$ measuring the relative market share of the two regions. This allows us to write the distribution function $B_{s}(\theta)$ for the South as a simple transformation of that of the North.

$$
B^{S}(\theta)-\gamma B(\theta-S)
$$

Aggregate consumer welfare in the South is then given by

(3) $\mathrm{U}^{\mathrm{s}}(\underline{\theta}, \bar{\theta})=\gamma \int_{\theta}^{\bar{\theta}} \mathrm{B}(\dot{\theta}-\mathrm{s}) \mathrm{d} \theta$.

We assume that all innovations take place in the North. This is not cerribly restrictive provided that the North has a sufficiently strong comparative advantage in research and development or that the South can appropriately discriminate between domestic and forelgn firms in the application of its patent laws. As both of these are realistic features of the current regime, we can concentrate on the decisions of Northern Eirms alone. We assume that there is an infinite supply of potential innovating firms, with each existing firm Identified by the technology it has developed. There is a fixed cost $c$ required to develop each technology; marginal costs of 
production will not play an interesting role for innovating firms, so we will ignore them. These fixed costs are treated parametrically by the firms, evon though an expansion of the range $[\hat{\theta}, \bar{\theta}]$ tends to drive $c$ up as the costs of resources used in the innovation process are bid up. So we will write c$c(\bar{\theta}-\theta)$, with $c^{\prime}>0$ and $c^{\prime \prime}>0$. This "congestion" effect acts like an externality, and will play an important role in the analysis. Its purpose is to capture the reality that the resources used in R\&D are not in perfectly elastic supply.

Consider the pricing strategy of a firm which has developed and patented a certain technology. If patent protection were perfect, the firm could capture the entire consumer surplus by charging a price of unity (technically, unity minus epsilon). Since patent protection never provides for full monopoly, 5 it is preferable to work with a model in which the firm can capture only a fraction of consumer surplus and charges a price lower than vality. A simple way to link the patent laws to th. pricing behavior of firms is as follows. Suppose the innovator faces a large fringe of potential imitators in the North, each of which can mimic the former by incurring unit costs of $a<1$ and no fixed costs. The parameter $\alpha$ can be thought of in part as capturing the (expected) unit costs incurred by imitators if they are brought to court and successfully prosecuted. In this sense, $\alpha$ parameterizes the restrictiveness of the prevailing patent laws in the North, with higher a associated with more complete patent protection. The analogous role in the South is played by the parameter $\beta$. Since the innovator's marginal costs are assumed zero (or, less restrictively, lower than the imitators), he will

5. In practice, even full patent righes are likely to confer only limited protection against imitators and fail to internalize R\&D spillovers. See Dasgupta (1988) and Jaffe (1986). 
always have the incentive to charge the IImit-prices a $e(0,1)$ and $\beta,(0,1)$ In the the two reglons, respectively. ${ }^{6}$ Hence the market equilibrium is similar to that with contestable markets: for each technology in the produced range, the incumbent firm (the innovator) charges the price which equals the unit cost of potential entrants. The costs of potential imitators are in turn determined by the restrictiveness of prevailing patent laws.

Tozal Northern profits can then be written as:

(4) $\Pi(\theta, \bar{\theta})-\int_{\theta}^{\bar{\theta}}[\alpha B(\theta)+\beta \gamma B(\theta-S)] d \theta-[\bar{\theta}-\theta] c($.$) .$

We assume that entry into new technologies, as opposed to already developed ones, is free. Firms enter until revenues just cover fixed costs. This allows us to determine the range of existing technologies by imposing the following zero-profit conditions.

(5) $a B(\theta)+\beta \gamma B(\underline{\theta}-S)-c(\bar{\theta}-\underline{\theta})-0$,

(6) $a B(\bar{\theta})+\beta \gamma B(\bar{\theta}-S) \cdot c(\bar{\theta} \cdot \theta)=0$,

which must hold at the edges of the range (see Figure 1 ). Provided $B(\theta)$ is single-peaked and not truncated, (5) and (6) together determine the range $(\ell$. $\bar{\theta}]$ of technologies which firms will find in their interest to develop. We assume that $s$ or $\gamma$ are small enough to ensure that the range of profitable technologies is indeed a continuous one. Notice that as long as $\beta>0$, the

6. Notice the implication that firms can charge different prices in different regions. This requires that Southern imitators not be able to market their output in the North. The justification is that patent restrictions apply to all sales within a region, irrespective of whether they originate from home or Foreign firms. This is consistent with the Paris Convention. Further, in the U.S., importation of a product that uses a domestically-patented process is forbidden. 
$-8-$

presence of the South allows the North to exploit a wider range of technologies, as fixed costs can be spread on a larger base. For the same reason, Northern firms will always market their products in the South, even if the degree of patent protection there is substantially lower than in their home market.

Soclal welfare in the North is the sum of consumer benefits and profits, and can be stated as a function of the range of discovered technologies:

(7) $\mathrm{w}^{\mathrm{n}}(\theta, \bar{\theta})-\int_{\underline{\theta}}^{\bar{\theta}}[\mathrm{B}(\theta)+\beta \gamma \mathrm{B}(\theta-\mathrm{s})] \mathrm{d} \theta-[\bar{\theta}-\theta] \mathrm{c}($.$) .$

The corresponding expression for the South is:

(8) $W^{S}(\theta, \bar{\theta})-\int_{\underline{\theta}}^{\bar{\theta}}(1-\beta) B_{s}(\theta) d \theta-\gamma \int_{\underline{\theta}}^{\bar{\theta}}(1-\beta) B(\theta-S) d \theta$.

Note that $\beta \gamma \int B(\theta-S) d \theta$ represents the transfer of $F$ ofits from the South to the North and is therefore subtracted from Southern welfare.

\section{Comparative Statics for the Range of Technologies}

The policy instruments in this model are $\alpha$ and $\beta$, which parameterize the degree of patent protection provided in the two regions. They affect the levels of welfare in the Nortin and South through their influence on the range of innovations, and, in the case of $\beta$, through the magnitude of the profit transfers from the South to the North. We start by analyzing the response of $\theta$ and $\bar{\theta}$ to changes in exogenous parameters.

We first note that equations (5) and (6) yield a relationship between marginal benefits in the two regions:

(9) $[B(\theta)-B(\bar{\theta})]=\gamma(\beta / \alpha)[B(\bar{\theta}-S) \cdot B(\theta-S)]$. 
The expressions in the square brackets capture the difference between marginal consumer benefits at the edges of the range for the two ceglons. Suppose that the South did not exist $(\gamma=0)$, that it did not provide any patent protection $(\beta-0)$, or that its tastes ware identical to the North's $(S-C)$. Then (9) would require equality between $B(\phi)$ and $B(\bar{\theta})$. This equates the marginal consumer benefits (in the North) at each end of the range. When the South enters the picture, however, this equality need no longer hold; as we shall see, the range of produced innovations beromes skewed away from Northern tastes and towards Southern tastes. The larger is the Southern market $(\gamma)$, the taste differential (S), and the relative level of Southern patent protection $(\beta / \alpha)$, the more pronounced this becomes.

As a final preliminary, a note is warranted regarding the sign of the partial derivative of the benefit function $B($.$) , as this plays an important$ role in the following analysis. With a symmetric, single-peaked distribution function, $B^{\prime}(\theta)$ is positive or negative depending on which side of the mean $\theta$ lies. We will henceforth assume that $\bar{\theta}$ and $(\bar{\theta}-S)$ will always lie to the right, and $\underline{\theta}$ and $(\underline{\theta}-S)$ always to the left, of the mean of $B(\theta) .7$ This ensures that

$$
\mathrm{B}^{\prime}(\bar{\theta})<0, \quad \mathrm{~B}^{\prime}(\bar{\theta}-\mathrm{S})<0, \quad \mathrm{~B}^{\prime}(\theta)>0, \quad \mathrm{~B}^{\prime}(\theta-\mathrm{S})>0 .
$$

An interpretation of these conditions in economic terms is that the marginal benefit from innovations falls as the range of innovations becomes broader. They will always hold for a distribution like the normal one, provided $S$ is not too large.

(1) Effects of Increased Northern Patent Protection. We differentiate

7. This is in fact too restrictive for the results to be discussed below to hold. A weaker condition will generally suffice. 
(5)-(6) totally to perform comparative-statics analysis. Let the determinant of the syster be denoted by $\Delta<0$ (see the appendix). Then the effect of changes in $a$ on the boundaries of the range of innovations can be determined as follows:

(10) $d \theta / d a=(1 / \Delta)\left|-B(\theta)\left[\alpha B^{\prime}(\bar{\theta})+\beta \gamma B^{\prime}(\bar{\theta}-S)\right]+[B(\theta)-B(\bar{\theta})] c^{\prime}\right|<0$.
$(-) \quad(-)$
$(-)$
$(0 /+)$

As discussed above, $B^{\prime}(\bar{\theta})$ and $B^{\prime}(\bar{\theta}-S)$ are both be negative. Moreover, we will see that $[B(\ell)-B(\bar{\theta})] \geq 0$ (i.e. the range will be generally skewed to the right). These ensure that an increase in patent protection in the North will unambiguously reduce the lower bound, increasing the number of innovations on the left of the distribution. These are the innovations which are not greatly valued in the South.

Some ambiguity exists, however, with the upper bound:

$$
\begin{array}{r}
\text { (11) } \left.\mathrm{d} \bar{\theta} / \mathrm{da}-(1 / \Delta) !-\mathrm{B}(\bar{\theta})\left[\alpha \mathrm{B}^{\prime}(\underline{\theta})+\beta \gamma \mathrm{B}^{\prime}(\theta-S)\right]+[\mathrm{B}(\theta)-\mathrm{B}(\bar{\theta})] \mathrm{c}^{\prime}\right), \\
(-)(-)(+) \quad(0 /+)
\end{array}
$$

which is positive only if $[B(\theta)-B(\bar{\theta})] c^{\prime}$ is not too large. The interpretation is as follows. If the range of innovations is already too skewed to the right (1.e. towards Southern tastes) so that $[B(\theta) \cdot B(\bar{\theta})] \gg$ 0 , an increase in Northern patent protection may well lead to some of the innovations that are relatively more suitable to the South to drop out. This possibility is due to the crowding-out of existing products as the expansion of the range of innovative activity increases costs incurred by all incumbents. When this does not happen, an increase in a will generate more innovation on the upper end of the range as well. 
Further, combining expressions (10) and (11). it can be seen that the overall range of innovations unambiguously expands as a increases:

$$
\begin{aligned}
& d \bar{\theta} / d \alpha-d \ell / d a \\
& -(1 / \Delta)\left(B(\bar{\theta})\left[a B^{\prime}(\ell)+\beta \gamma B^{\prime}(\ell-S)\right]-B(\ell)\left[\alpha B^{\prime}(\bar{\theta})+\beta \gamma B^{\prime}(\bar{\theta}-S)\right]\right\}>0 .
\end{aligned}
$$

Therefore, patent protection in the North w11l increase Innovative activity, but may do so at the expense of some products which are particularly sulted to Southern requirements.

(ii) Effects of Increased Southern Patent Protection. The effects of patent protection in the Suuth are similar to those discussed above, except that they get moderated by the parameter $\gamma$. Hence, an increase in $\beta$ unambiguously increases the innovations that are more approprlate to southern needs (1.e. those on the right of the distribution):

$$
\mathrm{d} \bar{\theta} / \mathrm{d} \beta=(\gamma / \Delta)\left(\cdot \mathrm{B}(\bar{\theta}-S)\left[\alpha B^{\prime}(\underline{\theta})+\beta \gamma B^{\prime}(\underline{\theta}-S)\right]+[B(\theta-S)-B(\bar{\theta}-S)] C^{\prime}\right)>0
$$

The ambiguity now exists with respect to innovations near the lower end of the range:

$$
d \ell / d \beta=(\gamma / \Delta)\left(-B(\varepsilon-S)\left[\alpha B^{\prime}(\bar{\theta})+\beta_{\gamma} B^{\prime}(\bar{\theta}-S)\right]+[B(\theta-S)-B(\bar{\theta}-S)] c^{\prime}\right)
$$

which can be positive if the (negative) term $[B(\theta-S)-B(\bar{\theta}-S)] c^{\prime}$ is sufficiently large in absolute value. Notice that $[B(\theta-S)-B(\bar{\theta}-S)]$ is the difference between Southern marginal consumer benefits at the two ends of the innovation range. The likelihood that increased patent protection in the South will lead to some of the products favored in the North to drop out increases with: (i) the degree to which existing innovations mirror Northern requirements; (ii) the diffferences in tastes between the two regions; and 
(11i) the magnitude of the cost increase as the range broadens.

Once again, Irrespective of whethe: some innovations drop out, the range itself must broader:

(15) $d \bar{\theta} / d \beta \cdot d \theta / d \beta$

$=(\gamma / \Delta)\left(B(\bar{\theta}-S)\left[\alpha B^{\prime}(\theta)+\beta \gamma B^{\prime}(\theta-S)\right]-B(\theta-S)\left[\alpha B^{\prime}(\bar{\theta})+\beta \gamma B^{\prime}(\bar{\theta}-S)\right]\right\}>0$,

but the presence of the South skews the range to the right relative to the mean of the $B(\theta)$ distribution.

(111) Effects of Change in Relative Market Sizes. As far as the range of innovations is concerned, the relative market-size parameter $\gamma$ enters the model in much the same way that $\beta$ does: an increase in $\gamma$, just as an increase in $\beta$, raises the weight placed by Northern firms on Southern tastes. Therefore, the comparative-statics results are much the same. The range of Innovaitons broadens unambiguously $(d \bar{\theta} / d \gamma-d \ell / d \gamma>0)$, and more of the potential Innovations particularly sulted to Southern tastes are developed $(d \bar{\theta} / d \gamma>0)$. And some of the innovations at the other end may drop out if the term $\beta[B(\theta-S)-B(\bar{\theta}-S)] c^{\prime}$ is sufficiently negative.

(iv) Effects of Change in Tastes. Taste differences between the two regions are captured here by the parameter $S$; the larger is $S$, the greater the taste difference. We would expect that as $S$ increases, the range of Innovazions becomes progressively more skewed away from Northern tastes. This is Indeed the case, as both the lower and upper bound of the range unambiguously move to the right (1.e., $d \theta / d S>0$ and $d \bar{\theta} / \dot{a} S>0)$. Further, one can show that when $\gamma \beta<\alpha$, we must have $d \theta / d S<1$ and $d \bar{\theta} / d S<1$.

What about the number of innovations, or the size of the range? The comparative-statics yield: 


$$
\begin{array}{r}
d \bar{\theta} / d S-d \theta / d S-(\alpha \beta \gamma / \Delta)\left[B^{\prime}(\theta) B^{\prime}(\bar{\theta}-S)-B^{\prime}(\bar{\theta}) B^{\prime}(\theta-S)\right], \\
(-) \quad(-) \quad(-)
\end{array}
$$

whose sign looks ambiguous at first sight. With a symmetric distribution, however, more can be said. Remember that the range of innovaticns [e, $\bar{\theta}]$ will generally be skewed to the right relative to the mean of $B(\theta)$ (due to the South's influence). This allows us to gauge the relative slopes along the distribution as follows: $\left|B^{\prime}(\theta)\right|>\left|B^{\prime}(\bar{\theta})\right|$ and $\left|B^{\prime}(\bar{\theta}-S)\right|>\left|B^{\prime}(\theta-S)\right|$.

Therefore the first term in the square brackets dominates and the sign of the expression must be positive. An increase in taste differences between the North and South widens the range of innovations that are developed.

To conclude this section, there is reason to think that there w11l be both cooperative and non-cooperative elements in any North-South bargain over patent protection. To some extent, patent protection in the North and South are substitutes for each other, as either increases the incentive of Northern firms to engage in innovative activity. The closer is $\gamma$ to unity, the greater impact Southern patent protection has on the profitability of Northern innovation. But Northern and Southern patents are imperfect substitutes for each other. Everything else being the same, both regions would prefer to have the range of innovations be as congruent with their tastes and requirements as possible. Southern patent protection, for example, not only increases the range of innovations, but also skews it away from Northern preferences. As we shall see, this may provide a rationale for the South to provide protection even when the incentives to free ride on Northern patents are strong.

In the rest of the paper, the comparative-statics results developed here will play an important role. We draw attention in particular to the 
significance of the ambiguity in the signs of $d \bar{\theta} / d a$ and $d \ell / d \beta$. A sufficient condition for the reaction curves of the two regions to slope down in a Nash equilibrium will be that $d \bar{\theta} / d a>0$ and $d \theta / d \beta<0$. We will treat this as the benchmark. But when $d \bar{\theta} / d \alpha<0$ and/or $d \theta / d \beta>0$, one or both of the reaction curves could slope up. In the latter situation, increased patent protection by one region leads to the elimination of innovations in the other region that are favored highly compared to the ones that are being stimulated. In such circumstances, much of the conventional wisdom can be reversed.

Since many of the analytical expressions we derive below are of ambiguous sign, we will fortify our discussion of the channels at work with a set of numerical simulations. Our simulations assume that consumer preferences in the North are distributed according to the standard normal distribution, and that the cost function is given by $c(\bar{\theta}-\theta)-[\exp (\bar{\theta}-\ell)] / 2000$. In our central case, $S=1.2$ and $\gamma-0.3$. That is, Southern tastes are assumed to be centered 1.2 standard deviations away from the mean of Northern tastes, and the South is taken to represent a market 30 percent as big as the North. (These values enslize that the reaction functions are both negatively sloped around the Nash equilibrium.) We will also refer to an alternative case with more extreme taste differences, where $S-2$ and $\gamma=0.12$, in which the Northern reaction function will be positively sloped.

\section{Welfare Analysis}

Suppose a benevolent global dictator were to assign patent rights to the two regions in accordance with a conventional social welfare function. Would she impose equal rates of patent protection?

To begin with, let the global welfare function (W) be written as an 
equally-weighted sum of welfare in the two reglons:

$$
\text { (17) } \begin{aligned}
\mathrm{W}(\ell, \bar{\theta}) & -\int_{\underline{\theta}}^{\bar{\theta}}\left[\mathrm{B}(\theta)+\beta_{\gamma} \mathrm{B}(\theta-\mathrm{s})\right] \mathrm{d} \theta \cdot[\bar{\theta}-\theta] \mathrm{c}(.)+\int_{\underline{\theta}}^{\bar{\theta}} \gamma(1-\beta) \mathrm{B}(\theta-\mathrm{S}) \mathrm{d} \theta \\
& =\int_{\underline{\theta}}^{\bar{\theta}} \mathrm{B}(\theta) \mathrm{d} \theta+\int_{\ell}^{\theta} \gamma \mathrm{B}(\theta-S) \mathrm{d} \theta-[\bar{\theta}-\theta] \mathrm{c}(.) .
\end{aligned}
$$

Since we have two independent instruments, $\alpha$ and $\beta$, to control two targets, $\theta$ and $\bar{\theta}$, we migint as well assume that we can exercise direct control over the range of innovations. The first-order conditions with respect to $\theta$ and $\bar{\theta}$, respectively, are:

(18) $B(\underline{\theta})+\gamma B(\underline{\theta}-S)-c-[\bar{\theta}-\underline{\theta}] c^{\prime}=0$,

(19) $B(\bar{\theta})+\gamma B(\bar{\theta}-S)-c-[\bar{\theta}-\underline{\theta}] c^{\prime}-0$,

Setting (18) and (19) equal to each other yields:

(20) $[B(\theta)-B(\bar{\theta})] /[B(\bar{\theta}-S)-B(\theta-S)]-\gamma$.

Hence the smaller is $\gamma$, the less off-center is the range of innovations relative to Northern tastes. Putting (20) together with equation (9), we are left with the equality $\gamma-\gamma(\beta / \alpha)$, which requires $\alpha-\beta$. Therefore, when the global welfare function is strictly utilitarian, global optimality does indeed require equal levels of patent protection in the two regions. Note that this holds irrespective of the sizes or tastes of the two regions.

The explanation is as follows. Since we are maximizing total benefits in the North and the South, the relative size of the South, $\gamma$, also represents the relative weight we place on its welfare. But firms weight the two regions according to their relative profitability, which is captured by the ratio 
$\gamma(\beta / \alpha)$. Firm behavior coincides with social optimality only when $\alpha=\beta$.

We can say more about the properties of the optimal levels of patent protection. Substituting for $c($.$) from (5) and (6), we can rewrite equations$ (18) and (19) as follows:

$$
\begin{aligned}
& \text { (18') }(1-\alpha) \mathrm{B}(\theta)+(1-\beta) \gamma \mathrm{B}(\underline{\theta}-\mathrm{S})-[\bar{\theta}-\theta] \mathrm{c}^{\prime} \\
& \left(19^{\prime}\right) \quad(1-\alpha) \mathrm{B}(\bar{\theta})+(1-\beta) \gamma \mathrm{B}(\bar{\theta}-\mathrm{S})=[\bar{\theta}-\theta] \mathrm{c}^{\prime} .
\end{aligned}
$$

When costs are not increasing in the range of innovations $\left(c^{\prime}-0\right)$, the righthand side is zero, implying $\alpha-\beta-1$. With constant costs, there are no distortions in the market, and firms should be allowed to capture the entire consumer surplus. Patent protection is complete. But when congestion effects are present $\left(c^{\prime}>0\right)$, firms confer a negative externality on each other. Each additional firm that enters drives up the costs of incumbents, so that if patent protection were complete, there would be too many firms. In this case, since the right-hand side of $\left(18^{\prime}\right)$ and $\left(19^{\circ}\right)$ is positive, social optimality requires $\alpha-\beta<1$. Patent protection is incomplete.

This is, of course, a rather different story from that commonly given as to why governments provide less than full patent protection. The usual explanation has to do with reducing the monopoly power of firms to which protection has been granted and enabling innovations to be readily diffused after a fixed number of years. But, formally, these explanations can be reconciled with the present framework. We could presume for example that, due to technological spillovers, the research costs of each firm are a decreasing function of the quantity of publicly available technology. As $\alpha$ and $\beta$ increase, patents become more restrictive and fewer technologies remain in the public domain. Therefore, costs of all firms possibly increase. 8 This is 
quite simliar to the effect that operates in the present model.

Now suppose that the global dictator is also egalitarian, and that she values the poor South's welfare more than the North's. How would this change the relationship between the optimal $\alpha$ and $\beta$ ?

Let the relative weight attached to the South's welfare be denoted $\phi$, with $\phi>1$. Global welfare can now be written as

$$
\begin{aligned}
\mathrm{W}(\underline{\theta}, \bar{\theta}) & =\int_{\underline{\theta}}^{\bar{\theta}}[\mathrm{B}(\theta)+\beta \gamma \mathrm{B}(\theta-\mathrm{S})] \mathrm{d} \theta-[\bar{\theta}-\theta] \mathrm{c}(.)+\phi \int_{\underline{\theta}}^{\bar{\theta}} \gamma(1-\beta) \mathrm{B}(\theta-\mathrm{S}) \mathrm{d} \theta \\
& =\int_{\underline{\theta}}^{\bar{\theta}} \mathrm{B}(\theta) \mathrm{d} \theta+\Phi \int_{\underline{\theta}}^{\bar{\theta}} \gamma(\theta-\mathrm{S}) \mathrm{d} \theta-[\bar{\theta} \cdot \underline{\theta}] \mathrm{C}(.),
\end{aligned}
$$

where $\Phi=[\phi-(\phi-1) \beta]$. Note that $\Phi>1$ as long as $\beta<1$. Therefore the only difference with the earlier objective function is that now the gross benefits of the South--gross in the sense that profit transfers to the North are not included--receives a weight larger than one ( $\Phi)$. The analogue of (20) now is

$$
\begin{aligned}
\left(20^{\prime}\right) \quad[B(\underline{\theta})-B(\bar{\theta})] /[B(\bar{\theta}-S)-B(\underline{\theta}-S)] \\
=\gamma \Phi-\left[\gamma(1-\alpha)(\mu+\nu) \int B(\theta-S) d \theta\right][B(\bar{\theta}-S)-B(\underline{\theta}-S)]^{-1},
\end{aligned}
$$

where $\mu=\mathrm{d} \beta / \mathrm{d} \vec{\theta}>0$ and $\nu=\mathrm{d} \beta / \mathrm{d} \theta>0$ (see the appendix). Notice that since $\bar{\theta}$ and $\underline{\theta}$ are now treated directly as policy variables, the two derivatives $\mu$ and $\nu$ refer to the implied changes in $\beta$ needed to bring about the desired adjustments in the boundaries. (They are total derivatives, as $\alpha$ is being

8. More specifically, two effects can be identified as $\alpha$ and $\beta$ are raised. The first, which argues in favor of patents, is that more research is undertaken. The second, which argues against patents, is that less of it becomes available to all firms and costs are not sufficiently reduced. When patent protection is nearly complete, a small decrease can have second-order effects in terms of the first, but first-order effects in terms of the second. This would call for incomplete patent protection. 
endogenously adjusted as well.) Putting this together with (9) and simplifying, we get:

$$
\begin{aligned}
& \beta=\alpha \text {, with } \\
& \Omega-[1+\alpha(\phi-1)]^{-1}\left(\phi+(1-\phi)(\beta+\nu) \int B(\theta-S) d \theta[B(\bar{\theta}-S)-B(\theta-S)]^{-1}\right) .
\end{aligned}
$$
$(+)$
$(-) \quad(+)$
$(+)$
$(+)$

Notice that $\phi>1+a(\phi-1)$, so that the effect of the first term in the curly brackets (i.e. $\phi$ ) is to raise $\beta$ relative to $\alpha$. This comes from the desire to skew the innovation range towards Southern tasces. But as $\beta$ increases, so do profit transfers to the North, and this effect is captured by the long second term in the curly brackets, which is negative and subtracts from $\phi$. Whether $\Omega$ on the whole is bigger or smaller than unity cannot be determined a priori. But the closer are Southern preferences to Northern ones, the greater the likelihood that $\Omega$ will be less than one, and that $\beta$ will fall short of $\alpha$. This can be seen from (22): $[B(\bar{\theta}-S)-B(\ell-S)]$ becomes smaller (and hence its inverse larger) as $S$ goes to zero (see [9]). ${ }^{9}$ As Northern and Southern preferences become more alike, then, the free-riding motive of the South exerts a growing influence. But when Southern preferences for technology differ substantially from those of the North, the globally optimal $\beta$ could we11 exceed $a$.

While the theoretical possibilities are unconstrained, numerical simulations with the specification described above yield the result that as $\phi$ increases, Northern protection is consistently raised while Southern

9. There is of course nothing here that would stop $\beta$ from turning negative. A planner who values the South's welfare sufficiently will in this case try to enrich that region by engineering reverse profit transfers from the North, while raising $\alpha$ to offset the adverse incentives on Northern R\&D. It may be natural to think of $\beta$ as being bound below by 0 . 
protection is reduced. These results are diplayed in Table 1 . With sufficiently large $\phi$, the global planner would allow the South to have a complete free-ride.

Therefore, when the global planner places more weight on the welfare of the South, there is no longer any reason to equate $a$ and $\beta$. But, unlike what may have been expected, there is no general reason to let the South provide lower levels of patent protection elther. The planner has to trade off the free-riding benefits to the South against the losses srising from reduced levels of investment in technologies that are particularly appropriate to poor countries.

\section{v. The Nash Equilibrium}

In the enviroment described above, patent protection in each block affects welfare in the other block. The questions we pose next are: what sort of patent laws emerge in the North and in the South if each region reacts to the other region's patent laws by optimizing over the level of patent protection in its own market? How is this equilibrium affected by the size and the taste preferences of the South? And how does it compare with the Pareto-optimal patent protection administered by a benevolent dictator? To answer these questions, we first develop the players' reaction functions under the assumption of Nash behavior.

(i) The Northern reaction function. The Northern planner choses a to maximize social welfare (7), taking $\beta$ as given. Optimally, the marginal cost of protection is set equal to the marginal benefit. We differentiate (7) with respect to $\alpha$, rearrange using (5) and (6) and set equal to zero: 


$$
W_{\alpha}^{n}-(1-\alpha)\left[B(\bar{\theta}) \bar{\theta}_{\alpha}-B(\theta) \theta_{\alpha}\right]-c^{\prime}[\bar{\theta}-\theta]\left[\bar{\theta}_{\alpha}-\theta_{\alpha}\right]=0,
$$

where we have introduced the following notation: $\bar{\theta}_{\alpha}=d \bar{\theta} / d \alpha, \theta_{\alpha}-d \theta / d \alpha$, etc. The second term of (23) represents the positive marginal cost of increased protection, an expression that is proportional to the size of the innovation range $[\bar{\theta}-\theta]$ and to the positive effect of $\alpha$ on the range $\left[\bar{\theta}_{\alpha}-\theta_{\alpha}\right]$. The first term represents the net marginal benefit that accrues on both sides of the range, and it is only (1-a) times the marginal consumer surplus (the term in brackets) because a proportion $\alpha$ of the increase in consumer surplus is dissipated in research costs by the marginal innovating firms. (Remember that zero-profit conditions hold at the edges of the ra:ige.) The marginal gain in consumer surplus due to an expansion of the range of innovations is composed of two effects: he lower range necessarily expands (to the left) after an increase in $\alpha$, thus increasing welfare. The upper range generally also expands (to the right) as firms can spread their coit on a larger base. But, as discussed in section III, because costs increase with the range of innovations, it is possible that the upper range retracts (to the left).

Let $\alpha^{*}$ stand for the North's optimal patent. When costs are not rising $\left(c^{\prime}=0\right),(23)$ is always positive for $\alpha<1$, implying that $\alpha^{\star}-1$. This would be the case where there are no congestion effects in R\&D. But with costs increasing with the range of research activity, $a^{*}<1$ since at $a-1$, the expression in (23) is negative. Moreover, when $\beta=0, \alpha^{*}$ is strictly positive, since at $\alpha=0, \underline{\theta}=\bar{\theta}$ and the second term of (23) is zero while the first is positive.

How does the North react to an increase in protection in the South? In general, but not always, the North will reduce protection in response, due to two considerations: (i) at the margin the positive effect of Northern protection on own welfare is attenuated, and (ii) research costs are increased 
as a result of highe: $\beta$. The ambiguity noted above with respect to the signs of $\bar{\theta}_{\alpha}$ and $\theta_{\beta}$, however, imply that effect (i) does not a! ays obtain, such that a decrease in $\alpha$ is sometimes undesirable. To see that, apply the implicit function theorem to (23) to get:

(24) $d \alpha^{*} / d \beta--w_{\alpha \beta}^{n} / w_{\alpha \alpha}^{n}$

where the denominator $w_{a \alpha}^{n}$ is negative by the second order condition. Hence, the slope of tine reaction function in (24) has the same sign as the numerator $w_{\alpha \beta}^{n}$. In order to evaluate the sign of $w_{\alpha \beta}^{n}$, we drop the terms corresponding to second derivatives of $\theta$ and $\bar{\theta}, 10$ on the assumption that these are likely to be of second-order impertance. $w_{\alpha \beta}^{\mathrm{n}}$ is then given by:

$$
w_{\alpha \beta}^{n}=(1-\alpha)\left[B^{\prime}(\bar{\theta}) \bar{\theta}_{\alpha} \bar{\theta}_{\beta}-B^{\prime}(\underline{\theta}) \underline{\theta}_{\alpha} \theta_{\beta}\right]-\left[c^{\prime}+c^{\prime} \cdot(\bar{\theta}-\theta)\right]\left[\bar{\theta}_{\alpha}-\underline{\theta}_{\alpha}\right]\left[\bar{\theta}_{\beta}-\theta_{\beta}\right]
$$

where the first term captures effect (i) and the second captures effect (ii) mentioned above. Expression (25) is negative in general, and positive only when $\bar{\theta}_{\alpha}$ is negative and large and/or $\underline{\theta}_{\beta}$ is positive and large.

The interpretation is as follows. In general, as the range of innovations widens, the marginal benefit of innovation drops on both sides of the range, discouraging protection. In this case, both ris effect and the rising R\&D costs contribute to a lessening of Northern ptotection. But when tastes are very different and $\alpha$ and $\beta$ are far apart, increased Southern protection can enhance marginal benefits of an increase in $\alpha$. This can occur in two types of situations: when $\theta_{\beta}>0$ and large, an increase in $\beta$ shifts the range away from Northern preferences and increased Northern protection can

10. In other words we assume $\underline{\theta}_{\alpha \alpha}=\underline{\theta}_{\alpha \beta}-\bar{\theta}_{\alpha \alpha}-\bar{\theta}_{\alpha \beta}-0$. This is somewhat analogous to the assumption of linear demand curves in standard oligopoly theory. We maintain this assumption throughout the paper. 
increase marginel revenue by recapturing the valuable technologles that would be lost otherwlse. And when $\bar{\theta}_{\alpha}<0$ and large enough, a reduction in $\alpha$ hurts the North by leading to the substitution of too many less valuable innovations on the upper side of the range. In these cases, the positive effect on marginal revenue can overtake the negative effect on marginal costs and it is possible that an increase in $\beta$ will be met with an Increase in $\alpha^{*}$ as the North attempts to shift the range of technologies away from Southern preferences.

The more general case is clearest when North-South tastes coincide (1.e S. -0). In this case, it is possible to show (see the appendix) that the Northern reaction function becomes linear in Southern protection and that it is unambiguousiy downard sloping. In particular, we get:

$$
d a^{*} / d \beta-1 / \gamma<0 \quad(\text { at } s-0)
$$

(ii) The Southern reaction function. Similarly, we can derive the firstorder condition for the Southern planner and the reaction function with respect to Northern protection. The problem is quite similar to the Northern problem, with the difference that the cost of increased protection is an Increased transfer to forelgners rather than an increased cost of research. Differentiating (8) with respect to $\beta$ and setting to zero, we have (assuming an interior solution for $\beta$ ):

$$
W_{\beta}^{S}=\gamma(1-\beta)\left[B(\bar{\theta}-S) \bar{\theta}_{\beta}-B(\underline{\theta}-S) \theta_{\beta}\right]-\gamma \int_{\underline{\theta}}^{\bar{\theta}} B(\theta-S) d \theta-0
$$

The second term represents the marginal cost of increased protection in terms of higher payments to the Innovating foreign firms. If there were no offsetting positive effect to Southern patent protection, $\beta^{*}$ would of course be optimally set to its lowest possible level as the South would simply free ride on Northern innovations. However, there are in genecal gains associated 
with protection and they are represented by the first term in equation (27). An Increase in $\beta$ Increases the range of innovations and tilts it cowards Southern tastes. 11 Note that the first term gets smaller with $\beta$, since only (1-B) of the consumer surplus is captured by the South. In particular, the marginal benefit of protection is zero at $\beta=1$ and therefore, $\beta^{*}$ is necessarily smaller than 1. Finally, note that $\beta^{*}$ can be zero in general but that it is certalnly positive when $a=0$. (This is because $w_{\beta}^{8}>0$, when $\alpha-\beta-0$.)

Thie slope of the Southern reaction function is given by:

$$
\mathrm{d} \beta * / \mathrm{d} \alpha-\mathrm{W}_{\alpha \beta}^{\mathrm{s}} / \mathrm{w}_{\beta \beta}^{\mathrm{s}}
$$

which--because the denominator is negative--has the same sign as the numerator. Ignoring again the second order terms in $\ell$ and $\bar{\theta}, W_{\alpha \beta}^{s}$ is given by:

$$
\mathrm{W}_{\alpha \beta}^{S}=(1-\beta)\left[B^{\prime}(\bar{\theta}-S) \bar{\theta}_{\alpha} \bar{\theta}_{\beta}-B^{\prime}(\theta-S) \theta_{\alpha} \theta_{\beta}\right] \cdot\left[B(\bar{\theta}-S) \bar{\theta}_{\alpha}-B(\theta-S) \theta_{\alpha}\right]
$$

which is negative when $\bar{\theta}_{\alpha}>0$ and/or $\theta_{\beta}<0$. However, (29) could be positive and it might be in the interests of the the South to react to stiffer Northern protection by increasing its own protection. This would occur when: (i) increased Northern protection shifts the range of innovations sufficiently away from Southern tastes $\left(\bar{\theta}_{\alpha}<0\right.$ and large); and when (ii) at the margin, a reduction in Southern protection would add on too many innovations on the less-valuable lower end of the range $\left(\theta_{\beta}>0\right.$ and large). Both situations are more likely to occur wheil North-South preferences are quite different. Again it is possible to show that with similar tastes $(S-0)$ :

11. The degree to which it does that depends, of course, in part on the relative size of the Southern market, $\gamma$ (see section III). 
(30) $d \beta^{*} / d \alpha-\gamma<0 \quad$ (at $s-0$ ).

(See the appendix.)

(iii) Comparative statics. When the Nash game described above is played, several types of equilibria may emerge, with both reaction functions sloping down, one of the reaction functions sloping up, or even both reaction functions sloping up. Here we will focus on small changes around equilibria in which both reaction functions slope down, presumably the case that best describes the current situation. Even in this case, however, a range of different comparative statics results are possible.

(iiia) The effect of taste differences. When North-South preferences get closer, both regions react by altering their levels of protection. There are several effects at play here and the global effect of a change in tastes cannot be completely determined. In order to describe the channels through which relative preferences affect the final outcome, use the implicit function theorem on (23) and (27) to get:

(31) $\partial \alpha^{*} / \partial S=-w_{\alpha S}^{n} / w_{\alpha \alpha}^{n}$,
(32) $\partial \beta^{*} / \partial S=-w_{\beta S}^{S} / w_{\beta \beta}^{S}$.

These determine the direction of shifts in the respective reaction functions. In both eqations, the expressions have the same sign as their numerators since the denominators are negative when the second-order conditions of the maximization problems are satisfied. The numerators a.e respectively given by:

$$
\begin{aligned}
& w_{\alpha S}^{n}=(1-\alpha)\left[B^{\prime}(\bar{\theta}) \bar{\theta}_{\alpha^{\theta}} \bar{\theta}_{S}-B^{\prime}(\underline{\theta}) \underline{\theta}_{\alpha} \underline{\theta}_{S}\right]-\left[c^{\prime}+c^{\prime \prime}(\bar{\theta}-\underline{\theta})\right]\left[\bar{\theta}_{\alpha}-\theta_{\alpha}\right]\left[\bar{\theta}_{S} S^{-\theta_{S}}\right] \\
& \text { (34) } \mathrm{W}_{\beta S}^{S}=\gamma(1-\beta)\left[B^{\prime}(\bar{\theta}-S)\left(\bar{\theta}_{S^{-1}}\right) \bar{\theta}_{\beta}-B^{\prime}(\underline{\theta}-S)\left(\underline{\theta}_{S^{-1}}\right) \underline{\theta}_{\beta}\right] \\
& \text { - } \boldsymbol{\gamma}\left[B(\bar{\theta}-S) \bar{\theta}_{S}-B(\theta-S) \theta_{S}-\int B^{\prime}(\theta-S) d \theta\right] \text {. }
\end{aligned}
$$

Let us first consider the effects of taste differences on Southern 
optimal protection. As North-South preferences get closer (1.e. S decreases), the South is affected through two channels, both of which generally discourage patent protection. (1) First, for a given level of protection, what must be paid to the foreign Innovators increases as $S$ decreases. This marginal cost effect is captured by the second term in (34): since protection becomes in a sense more expensive, there are incentives to decrease it. In effect, as the South becomes more similar to the North, its tax base becomes larger because the existing technologies--which are biased towards Northern tastes--now produce a higher consumer surplus. ${ }^{12}$ (ii) Second, the marginal benefit of Innovations at the ends of the range generally decrease. This is captured by the positive sign of the first term in (34). To see why, first remember that the range of innovations gets smaller, and that it shifts to the left by less than the shift in Southern preferences because the reduction in research costs assoclated with the smaller range forces the marginal firms (at the ends of the range) to service thinner markets. As a result, marginal welfare gets smaller at $\bar{\theta}$, and higher at $\theta$. Since in general the first effect dominates, optimal Southern protection will tend to decline.

As tastes get closer, the North is also affected through two channels. (i) First, the range of innovations necessarily shrinks, reducing the fixed cost of innovation for all technologies. This effect--captured by the second term in (33)--encourages the North to increase innovation in its most prefered technologies and this is achieved with higher protection. (11) The other effect--represented by the first term in brackets--captures the change in

12. To illustrate that, imagine that India and Brazil have similar rates of patent protection, but that Brazilian technological needs are closer to those of the North than is the case for India. Then the above considerations state that, given Northern influences on the existing range of technologies, a representative consumer in Brazil would have a larger consumer surplus and would be paying larger royalties to foreign firms. 
marginal welfare at the ends of the innovation range, and on net exerts a depressing effect on domestic patent protection: the lower end of the range widens ( $\theta$ decreases) allowing the North to capture new technologies that are less valuable at the margin. This reduces the need for patent protection as, in effect, the marginal productivity of protection falls. On the other hand, the upper end of the range retracts, increasing the marginal benefits at $\bar{\theta} .13$ This effect tends to encourage increased protection, but it is in general smaller than the depressing effect at the lower end of the innovation range (unless $\bar{\theta}_{S}$ is much larger than $\theta_{S}$ ). In sum, both the marginal cost and the marginal benefit of protection are reduced and the reaction of the North will depend on the relative importance of these effects.

Figure 2 illustrates the possible outcomes when $S$ increases. ${ }^{14}$ As NorthSouth preferences get further apart, the Southern reaction function shifts up while the Northern reaction function can either increase or decrease. The new equilibrium is either at a point like $B$ or $C$, with higher $\beta$ but ambiguous results in the North, or at a point like D with higher a but lower $\beta$. The only general conclusion that can be drawn when both reaction functions are downward sloping is that at least one of the two regions must increase its protection when $S$ gets larger. (Conversely, either $\alpha$ or $\beta$ must fall when $S$ gets smaller.) In our simulations we find that $\beta$ is generally increased while $a$ is fairly insensitive (decreasing slightly at first, but then increasing) as S becomes larger (see Table 2). Table 2 also diplays the possibility that the South may choose hipher levels of protection than the North if the taste

13. Note that this effect goes the other way when $\bar{\theta}_{\alpha}<0$.

14. This is drawn for the stable case where the South's reaction function is more steeply sloped than the North's. 
differences become pronounced enough.

(iiib) Changes in relative market size. A change in the relative size of the Southern market also has ambiguous effects on the equilibrium strategies when both reaction functions slope down. It is easy to verlfy that in that case

$$
\begin{aligned}
& \partial \alpha^{*} / \partial \gamma=-w_{\alpha \gamma}^{n} / w_{\alpha \alpha}^{n}--\beta w_{\alpha \beta}^{n} / \gamma w_{\alpha \alpha}^{n}<0, \\
& \partial \beta^{*} / \partial \gamma=-w_{\beta \gamma}^{s} / w_{\beta \beta}^{s} \\
& \quad-\beta\left((1-\beta)\left[B^{\prime}(\theta-S) \theta_{\beta}^{2}-B^{\prime}(\bar{\theta}-S) \bar{\theta}_{\beta}^{2}\right]+\left[B(\theta-S) \theta_{\beta}-B(\bar{\theta}-S) \bar{\theta}_{\beta}\right]\right) / w_{\beta \beta}^{s}<0
\end{aligned}
$$

In words, the reactions functions of both regions shift back when $\gamma$ increases. Hence, the level of patent protection must decline in at least one of the two regions. This implies that, somewhat paradoxically, an increase in the size of the South can lead to reduced protection in both the North and the South. From the North's perspective, as the Southern market enlarges the range of innovation widens beyond the most desirable level and it may make sense to reduce (costly) protection. But the South may have been expected to always increase $\beta$, as the costs of free riding now apparently become larger. This is not so because an increase in $\gamma$ also increases the benefits of free riding, as the profit transfers at the margin increase commensurately--see the South's first-order condition (27). Moreover, since $\gamma$ and $\beta$ are substitutes for each other in determining the technology range, it may be rational for the South to use the extra leverage provided by the increase in its market size to reduce profit transfers to the North (via a reduction in $\beta$ ).

Table 3 shows some simulation outcomes for the benchmark case. These are generally in line with conventional wisdom. As $\gamma$ is reduced, the South progressively reduces $\beta$, and eventually stops protection altogether.

(iv) The inefficiency of the Nash equilibrium. We end by demonstrating that the Nash equilibrium is inefficient fron the global standpoint. This is 
natural, given the spillovers involved. Protection in any one region profits the other region (when reaction functions are downward sloping). Since neither side takes into account these spillovers, there is $11 k e l y$ to be too little innovation. However, other possible effects go the other way: in particular, with $\alpha$ and $\beta$ different enough, wasteful competition sets in, and may lead to too much protection in both blocks.

To illustrate the effects at work, we evaluate the marginal (equallyweighted) welfare of our benevolent global dictator at the Nash equilibrium. Differentiating (17) with respect to $\alpha$ and then $\beta$, we have:

$$
\begin{aligned}
\mathrm{w}_{\beta}= & {\left[B(\bar{\theta})+\gamma B(\bar{\theta}-S)-c-(\bar{\theta}-\underline{\theta}) c^{\prime}\right] \bar{\theta}_{\beta} } \\
& +\left[-B(\underline{\theta})-\gamma B(\underline{\theta}-S)+c+(\bar{\theta}-\underline{\theta}) c^{\prime}\right] \theta_{\beta}, \\
\mathrm{w}_{\alpha}= & {\left[B(\bar{\theta})+\gamma B(\bar{\theta}-S)-c-(\bar{\theta}-\underline{\theta}) c^{\prime}\right] \bar{\theta}_{\alpha} } \\
& +\left[-B(\underline{\theta})-\gamma B(\underline{\theta}-S)+c+(\bar{\theta}-\underline{\theta}) c^{\prime}\right] \theta_{\alpha} .
\end{aligned}
$$

To evaluate (36) at the Nash equilibrium, we plug in (23). Then, provided that $\bar{\theta}_{\alpha}>0$ (which is a sufficlent but not necessary condition), the resulting expression can be shown to be positive for all $\beta<1$, including $\beta^{*}$ of the Nash equilibrium:

$$
\mathrm{W}_{\alpha}=\left[\alpha B(\bar{\theta})+\gamma^{B}(\bar{\theta}-S)-c\right] \bar{\theta}_{\alpha}-[\alpha B(\underline{\theta})+\gamma B(\underline{\theta}-S)-c] \underline{\theta}_{\alpha} .
$$

The expressions in the square brackets are positive from the zero-profit conditions (5)-(6). Thus, the North is generally underpatented from a world welfare point of view. The reason for that is simply that the Northern decision makers do not take into account the positive externality that innovations produce in the South. Note that when $\beta-1,(37)$ is equal to zero (using [5] and [6]). Only in this limiting case is the Northern patent optimal from a global point of view.

But it may be possible for the North to be overpatented. This can occur 
when $\bar{\theta}_{\alpha}<0$ and large. In this case, there is wasteful competition in protection as the North would be trying to shift the range of innovations towards its most preferred technologies.

The analysis is quite similar for the South. To evaiuate (35) at the Nash equilibrium, plug in (23) and (27), and rearrange to get:

$$
\mathrm{W}_{\beta}=(1-\alpha)\left[\mathrm{B}(\bar{\theta}) \bar{\theta}_{\alpha}-\mathrm{B}(\underline{\theta}) \underline{\theta}_{\alpha}\right]\left[\left(\bar{\theta}_{\beta} / \bar{\theta}_{\alpha}\right)-\left(\underline{\theta}_{\beta} / \underline{\theta}_{\alpha}\right)\right]+\gamma \int \mathrm{B}(\theta-\mathrm{S}) \mathrm{d} \theta .
$$

which is generally positive (when $\bar{\theta}_{\beta}>0$ and $\theta_{\alpha}<0$ ). Thus, in general, the South is underprotected because it ignores the positive effect of protection on Northern welfare. In particular, it is easy to verify that at $s-0$ (38) is unambiguously positive. However it is once again pussible that the South will be overprotected when $\bar{\theta}_{\beta}>0$ and/or $\theta_{\alpha}<0$.

\section{Concluding Remarks}

While the model analyzed here is quite simple, it leads to a rich array of comparative-statics results, some of which may appear counter-intultive at first sight. This is largely due to our emphasis on the dimension of technological choice: some of the usual free-riding considerations have to be qualified when we take into account the possibility that patent laws in the two regions affect not only the quantity of innovation, but also its quality. This becomes important when the two regions have differing technological needs. On the other hand, when the two regions are identical in preferences, the usual conclusions can be recovered.

The analysis leads tn several results, some of which can be listed as follows. First, an increase in patent protection in any of the two regions leads to an increase in innovative activity, as well as a greater fit between the available technologies and the preferences of the patenting region. By implication, this skews the technology range away from the needs of the other 
region. Second, while a strictly utilitarian global welfare function would assign Identical rates of paterit protection to the North and South, placing greater weight on the welfare of the South necessitates differential treatment. But it is not clear a priorl whether the South ought to have a lower or higher level of protection than the North. Third, when patent rules are set in an uncoordinated manner, it is possible that a narrowing of the gap between the technological preferences of the two regions will lead to lower rates nf patent protection in the North and the South. Similarly, an increase in the relative market size of the South can lead to a reduction in patent protection in both regions. 
APPENDIX

(a) We start by deriving the comparative statics properties of equations (5) and (6), when the endogenous varlables are $\bar{\theta}$ and $\ell$. Total differentiation ylelds:

$$
\begin{aligned}
& {\left[\begin{array}{c}
\alpha B^{\prime}(\theta)+\beta \gamma B^{\prime}(\theta-S)+c^{\prime}-c^{\prime} \\
c^{\prime} \\
\alpha B^{\prime}(\bar{\theta})+\beta \gamma B^{\prime}(\bar{\theta}-S) \cdot c^{\prime}
\end{array}\right]\left[\begin{array}{l}
d \underline{l} \\
d \bar{\theta}
\end{array}\right]} \\
& -\left[\begin{array}{c}
-B(\theta) d \alpha-\gamma B(\theta-S) d \beta-\beta B(\theta-S) d \gamma+\beta \gamma B^{\prime}(\theta-S) d S \\
-B(\bar{\theta}) d \alpha-\gamma B(\bar{\theta}-S) d \beta-\beta B(\bar{\theta}-S) d \gamma+\beta \gamma B^{\prime}(\bar{\theta}-S) d S
\end{array}\right]
\end{aligned}
$$

The determinant of the system, denoted by $\Delta$, is negative.

(b) Consider next the alternative wherein $\alpha$ and $\beta$ are treated as endogenous, targeted on specific $\bar{\theta}$ and $\theta$. Notice that $d a / d \bar{\theta}$, for example, is not simply the inverse of $\mathrm{d} \bar{\theta} / \mathrm{da}$ as different varlables are being held constant in each case; in the first case, $\beta$ is free to vary but $\theta$ is parametric; in the latter, $\theta$ adjusts endogenously while $\beta$ is held fixed. The system now looks 11ke:

$$
\left[\begin{array}{cc}
-B(\theta) & -\gamma B(\theta-S) \\
-B(\bar{\theta}) & -\gamma B(\bar{\theta}-S)
\end{array}\right]\left[\begin{array}{l}
d \alpha \\
d \beta
\end{array}\right]-\left[\begin{array}{l}
{\left[\alpha B^{\prime}(\underline{\theta})+\beta \gamma B^{\prime}(\underline{\theta}-S)+c^{\prime}\right] d \theta-c^{\prime} d \bar{\theta}} \\
c^{\prime} d \underline{d}+\left[a B^{\prime}(\bar{\theta})+\beta \gamma B^{\prime}(\bar{\theta}-S)-c^{\prime}\right] d \bar{\theta}
\end{array}\right]
$$

The determinant of the system is positive since $B(\bar{\theta} \cdot S)>B(\bar{\theta})$ and $B(\theta)>$ $B(\theta-S)$. It can be shown therefore that $(\mu+\nu)=(d \beta / d \bar{\theta}+d \beta / d \theta)$ is unambigucusly positive.

(c) The second-order conditions for the Northern and the Southern maximization problems are respectively:

(A1) $W_{\alpha \alpha}^{\mathrm{n}}=(1-\alpha)\left[B^{\prime}(\bar{\theta}) \bar{\theta} \alpha^{2}-B^{\prime}(\theta) \theta_{\alpha}{ }^{2}\right] \cdot\left(\bar{\theta}_{\alpha}-\theta_{\alpha}\right)\left[c^{\prime}+c^{\prime \prime}(\bar{\theta}-\theta)\right]<0$.

(A2) $\quad W_{\beta \beta}^{S}=\gamma(1-\beta)\left[B^{\prime}(\bar{\theta}-S) \bar{\theta}_{\beta}^{2}-B^{\prime}(\theta-S) \theta_{\beta}^{2}\right]-2 \gamma\left[B(\bar{\theta}-S) \bar{\theta}_{\beta}-B(\theta-S) \theta_{\beta}\right]$, 
which is necessarily negative when $\theta_{\beta}<0$. Otherwise, it is possible that (A2) will be positive, implying that $\beta^{*}$ goes to the corner solution $\beta^{*}-0$.

(d) Using (10), (11), (13) and (14), it is easy to verify that when S-0: $\bar{\theta}_{\beta}=-\underline{\theta}_{\beta} ; \bar{\theta}_{\alpha}--\underline{\theta}_{\alpha} ; \bar{\theta}_{S}--\underline{\theta}_{S} ; \gamma \bar{\theta}_{\alpha}-\bar{\theta}_{\beta} ;$ and $B^{\prime}(\bar{\theta})--B^{\prime}(\theta)$. Plugging those relationships into (25), (29), (A1) and (A2), (24) reduces to (26), and (28) becomes (30). In general, a Nash equilibrium does not exist in this case, as both reaction functions have the same slope. 
Baldwin, Robert E., 1988, "Other Issues: North-South Trade, Intellectual Property Rights, and Subsidies, " in Baldwin and J. David Richardson, eds., Issues in the Uruguay Round, NBER Conference Report, Cambridge, MA.

Benko, Robert P., 1988, "Intellectual Property Rights and the Uruguay Round," The Horld Economy 11, 217-231.

Chin, Judith C., and Gene M. Grossman, 1988, "Intellectual Property Rights and North-South Trade," NBER Working Paper No. 2769.

Desgupta, Partha, 1988, "Patents, Priority and Imitation Or, The Economics of Races And Waiting Games," Economic Journal 98, 66-80.

Hamilton, Colleen, and John Whalley, 1988, "Coalltions in the Uruguay Round: The Extent, Pros, and Cons of Developing Country Participation," NBER Working Paper No. 2751.

Jaffe, Adam, 1986, "Technological Opportunity and Spillovers of R\&D: Evidence from Firms' Patents, Profits, and Market Value," American Economic Review $76,984-1001$.

Kelly, Margaret, et al., 1988, Issues and Developments in International Trade Policy, IMF Occasional Paper No. 63, Washington, D.C.

Penrose, Edith T., 1951, The Economics of the International Patent System, Baltimore, The Johns Hopkins Press.

Vernon, Raymcnd, 1957, The International Patent System and Forelgn Policy, Study of the Subcomittee on Patents, Trademarks, and Copyrights of the Committee on the Judiciary, U.S. Senate, Washinbgton, D.C., Government Printing Office. 
Table 1: Globally Optimal Patent Rates

\begin{tabular}{|c|c|c|}
\hline$\phi$ & $\underset{\alpha}{\operatorname{central}} \operatorname{case}^{a}:$ & $\begin{array}{c}\text { extreme taste diff } \\
\alpha\end{array}$ \\
\hline $\begin{array}{l}1.0 \\
1.5 \\
5.0\end{array}$ & $\begin{array}{l}0.21 \\
0.31 \\
0.78\end{array}$ & $\begin{array}{l}0.21 \\
0.10 \\
0.00\end{array}$ \\
\hline
\end{tabular}

Notes: a $s-1.2 ; \gamma=0.30 . \quad$ b $s=2 ; \gamma=0.12$.

Table 2: Nash Equilibrium Solutions

\begin{tabular}{lll}
\hline & & \\
\hline & $\alpha$ & $\beta$ \\
\hline
\end{tabular}

a. central case ${ }^{a}$ :

$\begin{array}{lll}0.8 & 0.22 & 0.00 \\ 1.1 & 0.22 & 0.00 \\ 1.2 & 0.21 & 0.03 \\ 1.3 & 0.20 & 0.07 \\ 1.4 & 0.20 & 0.10 \\ 1.5 & 0.20 & 0.14 \\ 1.6 & 0.21 & 0.15\end{array}$

b. extreme taste diff

\begin{tabular}{lcc}
1.0 & 0.22 & 0.00 \\
1.8 & 0.23 & 0.00 \\
2.0 & 0.20 & 0.12 \\
2.2 & 0.20 & 0.26 \\
2.5 & 0.23 & 0.38 \\
\hline a $s=1.2 ; \gamma=0.30$. & b $s-2 ; \gamma=0.12$.
\end{tabular}

Notes: a $s=1.2 ; \gamma=0.30 . \quad$ b $s-2 ; \gamma=0.12$. 
Table 3: Nash Equilibrium Solutions

\begin{tabular}{ccc}
\hline & & \\
\hline$\gamma$ & $\alpha$ & $\beta$ \\
\hline central case $^{a}:$ & & \\
0.50 & & \\
0.40 & 0.20 & 0.08 \\
0.30 & 0.20 & 0.07 \\
0.25 & 0.21 & 0.03 \\
0.20 & 0.21 & 0.03 \\
& 0.21 & 0.00 \\
\hline
\end{tabular}

Note: a $\mathrm{s}-1.2 ; \mathrm{y}=0.30$. 


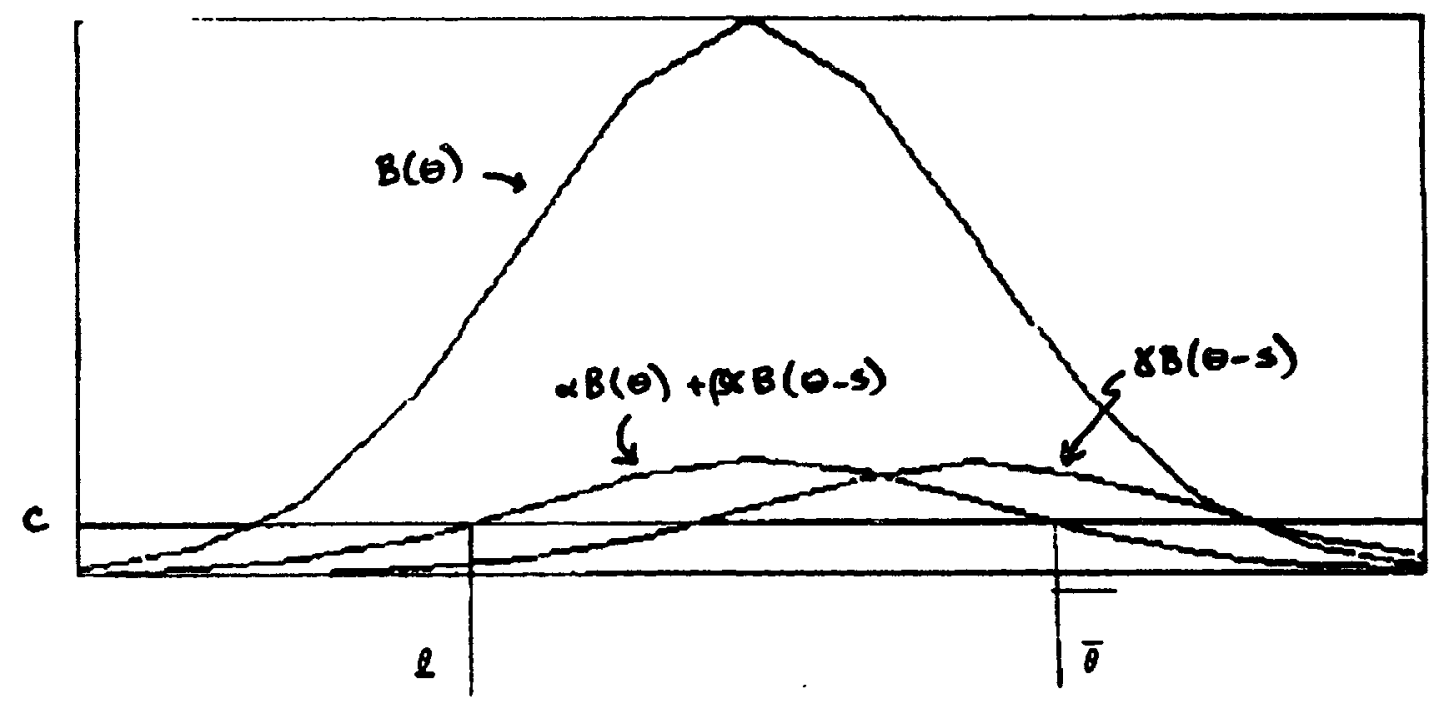

Flgure 1 


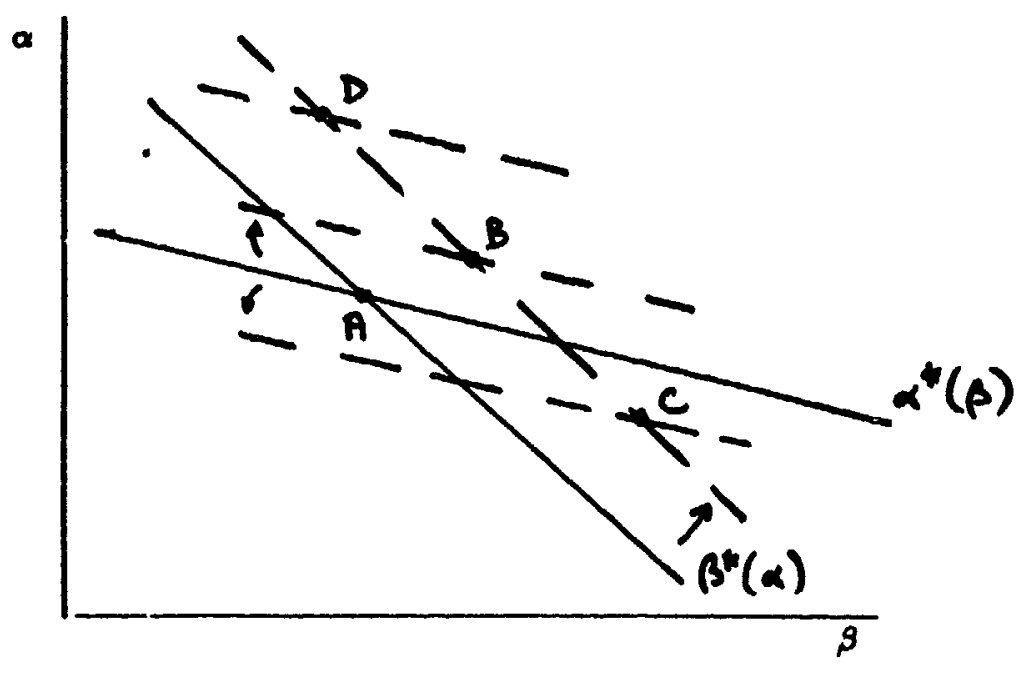

Elgure? 


\section{PPR Working Paper Sories}

Iitle.

WPS237 The Curricular Content of Primary Education in Developing Countries

WPS238 The Distributional Consequences of a Tax Reform On a VAT for Pakistan

WPS239 The Choice Between Unilateral and Multilateral Trade Liberalization Strategies

WPS240 The Public Role in Private Post-Secondary Education: A Review of Issues and Options

WPS241 The Effect of Job Training on Peruvian Women's Employment and Wages

WPS242 A Multi-Level Model of School Effectiveness in a Developing Country

WPS243 Averting Financial Crisis - Kuwait

WPS244 Do Caribbean Exporters Pay Higher Freight Costs?

WPS245 Developing a Partnership of Indigenous Peoples, Conservationists, and Land Use Planners in Latin America

WPS246 Causes of Adult Deaths in Developing Countries: A Review of Data and Methods

WPS247 Macroeconomic Policies for Structural Adjustment

WPS248 Private Investment, Government Policy, and Foreign Capital in Zimbabwe

WPS249 The Determinants of Hospital Costs: Ricardo Bitran-Dicowsky An Analysis of Ethiopia

WPS250 The Baker Plan: Progress, Shortcomings, and Future
Richard Hayes

Thierry Mertens

Geraldine Lockett Laura Rodrigues

Date

Contact

for paper

Aaron Benavot

June 1989

C. Cristobal 33640

August 1989

A. Bhalla 60359

July 1989

S. Torrijos 33709

August 1989

A. Bhalla

Emmanuel Jimenez

61059

July 1989

C. Cristobal 33640

July 1989

C. Cristobal 33640

July 1989

R. Simaan 72167

July 1989

J. Epps 33710

August 1989

S. Davis 38622

July 1989

S. Ainsworth 31091

R. Luz 61588

Mansoor Dailami

August 1989

M. Raggambi 61696

V. Israel 48121

August 1989

S. King-Watson 33730 
Iitle

WPS251 Patents, Appropriate Technology, and North-South Trade

WPS252 Do the Secondary Markets Believe in Life After Debt

WPS253 Public Debt, North and South

WPS254 Future Financing Needs of the Highly Indebted Countries

WPS255 The External Debt Difficulties of Low Income Africa

WPS256 Cash Debt Buybacks and the Insurance Value of Reserves

WPS257 Growth, External Debt, and the Real Sweder van Wijnbergen Exchange Rate in Mexico

WPS258 The Role of Voluntary Organizations in Development

L. David Brown

David C. Korten

WPS259 Dealing with Debt: The 1930s and the 1980s

WFS260 Growth, Debt, and Sovereign Risk in a Small, Open Economy

WPS261 Inflation, External Debt and Financial Sector Reform: A Quantitative Approach to Consistent Ritu Anand Fiscal Policy

WPS262 Adjustment and External Shocks in Ireland

Dermot McAleese

F. Desinond McCarthy

WPS263 How Has Instability in World Markets Peter Hazell Affected Agricultural Export Mauricio Jaramillo Producers in Developing Countries Amy Williamson

WPS264 Case Studies of Two Irrigation Herve Plusquellec Systems in Colombia: Their Performance and Transfer of Management to Users' Associations

WPS265 The Influence of Imperfect Competition in International Markets: Some Empirical Evidence
Contact

forpaper

August 1989

S. King-Watson 33730

August 1989

S. King-Watson 33730

August 1989

S. King-Watsen 33730

August 1989

S. King-Watson 33730

August 1989

S. King-Watson 33730

August 1989

M. Bailey 31854

August 1989

S. King-Watson 33730

August 1989

R. Luz 61588

August 1989

M. Divino 33739

August 1989

C. Spooner 30464 